NBER WORKING PAPER SERIES

\title{
FAST-FOOD RESTAURANT ADVERTISING ON TELEVISION AND ITS INFLUENCE ON YOUTH BODY COMPOSITION
}

\author{
Michael Grossman \\ Erdal Tekin \\ Roy Wada \\ Working Paper 18640 \\ http://www.nber.org/papers/w18640 \\ NATIONAL BUREAU OF ECONOMIC RESEARCH \\ 1050 Massachusetts Avenue \\ Cambridge, MA 02138 \\ December 2012
}

Research for this paper was supported by Grant \#65068 from the Robert Wood Johnson Foundation to the National Bureau of Economic Research. The views expressed herein are those of the authors and do not necessarily reflect the views of the National Bureau of Economic Research.

NBER working papers are circulated for discussion and comment purposes. They have not been peerreviewed or been subject to the review by the NBER Board of Directors that accompanies official NBER publications.

(C) 2012 by Michael Grossman, Erdal Tekin, and Roy Wada. All rights reserved. Short sections of text, not to exceed two paragraphs, may be quoted without explicit permission provided that full credit, including $(\odot)$ notice, is given to the source. 
Fast-Food Restaurant Advertising on Television and Its Influence on Youth Body Composition Michael Grossman, Erdal Tekin, and Roy Wada

NBER Working Paper No. 18640

December 2012

JEL No. I10,I18

\begin{abstract}
$\underline{\text { ABSTRACT }}$
We examine the effects of fast-food restaurant advertising on television on the body composition of adolescents as measured by percentage body fat (PBF) and to assess the sensitivity of these effects to using conventional measures of youth obesity based on body-mass index (BMI). We merge measures of body composition from bioelectrical-impedance analysis (BIA) and dual-energy x-ray absorptiometry (DXA) from the National Health and Nutrition Examination Survey with individual level data from the National Longitudinal Survey of Youth 1997 and data on local fast-food restaurant advertising on television from Competitive Media Reporting. Exposure to fast-food restaurant advertising on television causes statistically significant increases in PBF in adolescents. These results are consistent with those obtained by using BMI-based measures of obesity. The responsiveness to fast-food advertising is greater for PBF than for BMI. Males are more responsive to advertising than females regardless of the measure. A complete advertising ban on fast-food restaurants on television would reduce BMI by 2 percent and PBF by 3 percent. The elimination of the tax deductibility of food advertising costs would still leave a considerable number of youth exposed to fast-food advertising on television but would still result in non-trivial reductions in obesity.
\end{abstract}

Michael Grossman

Ph.D. Program in Economics

City University of New York Graduate Center

365 Fifth Avenue, 5th Floor

New York, NY 10016-4309

and NBER

mgrossman@gc.cuny.edu

Erdal Tekin

Department of Economics

Andrew Young School of Policy Studies

Georgia State University

P.O. Box 3992

Atlanta, GA 30302-3992

and NBER

tekin@gsu.edu
Roy Wada

Institute for Health Research and Policy

University of Illinois at Chicago

1747 West Roosevelt Road

Chicago, IL 60608

University of Illinois at Chicago

roywada@uic.edu 


\section{Introduction}

The proportion of youths between ages 12-19 who are obese has increased substantially in the U.S. from $5.0 \%$ in the mid-1970s to 18.1 percent in late 2000 s [1]. Suspected social causes of youth obesity include television advertising of unhealthy, nutrient-dense food on aimed at youths [2-4]. However, there has been little empirical evidence confirming such an effect until recently [5]. Accordingly, there has been a call from the White House Task Force on Childhood Obesity for additional research to demonstrate the link between advertising and food preferences and consumption by children and adolescents [6]. It is critical to provide further insights into the determinants of childhood obesity to help efforts of policy-makers in the design of more effective prevention policies. In a recent comprehensive study, Chou, Rashad, and Grossman [3] (CRG hereafter) use individual-level data from the National Longitudinal Survey of Youth 1997 (NLSY97), and find a positive and statistically significant association between fast-food restaurant advertising on television and youths' body mass index (BMI) and the probability of being obese (age-gender adjusted BMI ranking $\geq 95^{\text {th }}$ percentile). In another study, Andreyeva, Kelly, and Harris [5] use a sample of $5^{\text {th }}$ graders to document that soft drink and fast food television advertising is positively associated with the probability of being overweight (age-gender adjusted BMI ranking $\geq$ $85^{\text {th }}$ percentile) but not with bodyweight. They hypothesize that the weak association may be due to mismeasurement by BMI-based proxies for youth obesity.

While BMI is a widely accepted proxy for obesity, its limitation in distinguishing body fat and lean body mass is well-documented [7-11]. For example, BMI provides limited information on the degree of obesity in youths older than 10 years of age [12] 
while the association of BMI with body fatness in children differ substantially by gender, race, and age [13]. Thus, an increasing number of studies highlight the importance of using alternative measures of obesity for estimation purposes [8]. Several studies recommend using body composition or percentage body fat (PBF) for identification of youth overweight status [14].

Body composition, however, is considerably more difficult to measure and therefore has not been used by social scientists until recently. With the advancements in measurement technologies such as bioelectrical impedance analysis (BIA) and dual energy x-ray absorptiometry (DXA), the cost of measuring body composition has been reduced substantially and these measures are now available in several in large-scale surveys [15]. Using such data, social scientists have begun to compare the sensitivity of BMI-based findings to those based on body composition among adults $[16,17]$. To this date, no such sensitivity analysis has been conducted for youths. This is the first study to analyze the impact of fast-food advertising on body composition among youths. We also examine the sensitivity of the results obtained in CRG to our results using body composition measures of youth obesity.

\section{Methods}

To maintain comparability between the results in our paper and those in CRG, we draw on the same data sources as CRG.

\section{Primary Individual Data}

Individual-level data on youths aged 12 to 18 are obtained from the NLSY97, which contains a nationally representative sample of the U.S. youths. The initial sample in 1997 consists of 8,984 respondents aged 12 to 16 years old and contains extensive 
information about youth labor market behavior and educational attainment. A parent questionnaire with information on family background and a youth questionnaire on weekly hours of time spent in watching television for youths aged 12 to 14 were also administered in Round 1. Following the CRG, we use 1997 values for 1998 and 1999. The pooled sample size is 14,852 after observations with missing values are deleted and before advertising and state-level data are merged.

Fast-food restaurant television advertising data

We also obtain fast-food restaurant television advertising data from Competitive Media Reporting (CMR), the largest provider of advertising tracking services in the U.S. The advertising exposure, which is the number of seconds restaurant advertising aired per week per area, is collected for fast-food restaurant chains in the U.S. from 1996 to 1999. The exposure data are then converted to the number of hours per week.

The unit of area for advertising exposure is Designated Market Area (DMA), which is similar to a Metropolitan Statistical Area (MSA). Each DMA is a television market composed of counties (and occasionally part of counties). The top 75 out of about 210 DMAs are contained in the CMR database. Merging the advertising exposure data by DMA results in an analysis sample of 7,069 person-years. Using the information on weekly hours of television viewed in NLSY97, we calculate the weekly hours of fastfood advertising seen as follows:

$$
\mathrm{S}_{\mathrm{ijt}}=\left(\mathrm{T}_{\mathrm{ijt}} / 168\right) \mathrm{A}_{\mathrm{jt}} \mathrm{K}
$$

where $T_{i j t}$ is the weekly number of hours that the youth watches television, 168 is the number of hours in a week, $A_{j t}$ is the weekly number of hours of fast-food ads aired, and $\mathrm{K}$ is a positive constant. We take natural $\log$ to address positive skewness in $\mathrm{S}_{\mathrm{ijt}}$ and $\mathrm{T}_{\mathrm{ijt}}$ : 


$$
\ln \mathrm{S}_{\mathrm{ijt}}=\ln \mathrm{T}_{\mathrm{ijt}}-\ln 168+\ln \mathrm{A}_{\mathrm{jt}}+\ln \mathrm{K}
$$

The natural log transformation mitigates the influence of outliers, while also allowing each control variable to have a diminishing marginal effect on BMI or obesity. Therefore we have three key variables: $\ln (\mathrm{TV}$-time $), \ln ($ Ads-aired $)$, and $\ln ($ Ads-seen $)$.

Alternative measures of youth obesity

Body composition is described by the following identity:

$$
W \equiv B F+F F M
$$

where $\mathrm{W}$ is weight in kilograms, $\mathrm{BF}$ is body fat, and FFM is fat-free mass. PBF or percentage body fat is therefore,

$$
P B F=100 * \frac{B F}{B F+F F M} .
$$

We make use of both BIA and DXA measures of body composition that are available in the following waves of the National Health and Nutrition Examination Survey: NHANES III (1988 through 1994), NHANES 1999-2000, NHANES 2001-2002, and NHANES 2003-2004 [18].

In the BIA method, body composition is estimated by measuring the electrical resistance of a body to a weak electrical current [19]. The observed electrical resistance, which is negatively associated with FFM, is converted into FFM by entering it into a predetermined equation obtained from a multiple regression analysis along with a set of external measurements such as weight, height, age, and gender [20, 21]. After FFM is obtained from the prediction equation, BF is computed from the identity in equation (3), which is then combined with equation (4) to yield the following form:

$$
P B F \equiv 100 * \frac{B F}{W} \equiv 100 * \frac{W-F F M}{W} .
$$


Following previous studies $[16,17]$, we employ a prediction equation developed by Chumlea [20] for particular use with NHANES III. We also used a prediction equation developed by Boileau [22] for children aged 8 through 16 . These equations yield two sets of values for FFM and BF in NHANES.

A third set of body composition is obtained from the DXA measurement, also available in the NHANES. In this procedure, a complete body scan is administered in which two low dose $\mathrm{x}$-rays are absorbed at different rates by bone and soft tissue mass $[19,23]$. The computed amount of BF and FFM are directly reported in NHANES without the need for prediction equations.

Estimating alternative youth obesity measures

Because there is only one year of overlap between the NHANES waves and the CMR fast-food restaurant advertising data (1997-1999), we employ the procedures developed by Wada and Tekin [17] to obtain PBF measures in NLSY97, using information derived from NHANES. A similar strategy was also used by a recent study for examining the effect of body composition on European employment outcome [24].

In this procedure, we predict FFM and BF values in NLSY97 using regression coefficients obtained from the NHANES analysis. First, we separately regress FFM and body fat on weight, weight ${ }^{2}$, height, height ${ }^{2}$, age, age ${ }^{2}$, and weight*height in NHANES. This estimation is implemented for each of the six gender-race/ethnicity combinations (white non-Hispanic males, white non-Hispanic females, black non-Hispanic males, black non-Hispanic females, Hispanic males, and Hispanic females). We use persons of all ages in NHANES to increase the power in these regressions. The explanatory power in these regressions is high, with $\mathrm{R}^{2}$ values ranging between 0.80 and 0.90 . The 
coefficients from these regressions and the values of the independent variables in NLSY97 are then used to impute values for FFM and BF in NLSY97.

After computing FFM and BF in NLSY97, we use the three sets of BF and FFM estimates to calculate the corresponding PBFs using equations (4) and (5). Therefore, we obtain one measure of PBF based on DXA (PBF-D), another based on BIA with Chumlea's equation (PBF-C), and a third one based on BIA with Boileau's equation (PBF-B).

Conventional measures of youth obesity

Traditional obesity measures are BMI and an obesity indicator that equals one if the adolescent is obese (age-gender adjusted BMI ranking $\geq 95^{\text {th }}$ percentile). BMI is calculated as $\mathrm{W} / \mathrm{H}^{2}$, where $\mathrm{W}$ is weight in kilograms and $\mathrm{H}$ is height in meters.

\section{State-level data}

Following CRG, we include in our models state-level variables that are merged with the NLSY97 by state and year. These include the number of fast-food restaurants, the number of full-service restaurants, the price of a meal in each type of restaurant, an index of price of food at home, the price of cigarettes, and clean indoor air laws. Detailed descriptions of their sources, definitions, and relevance have been previously discussed $[25]$.

\section{Estimation strategy}

We use a multiple regression method. Given the large sample size, we fit linear probability models for binary obesity outcome. The coefficients from linear probability models are consistent estimates of average probability derivatives, but the standard errors are biased as a result of heteroskedasticity [26]. Thus, we report standard errors that are 
robust to any form of heteroskedasticity. We also employ sampling weights and cluster standard errors on DMA, given that the advertising variables are repeated within DMA. Our most comprehensive regression model is:

$$
Y_{i j t}=\gamma_{0}+\gamma_{1} \ln S_{i j t}+\gamma_{2} \ln T_{i j t}+\beta_{1} X_{i j t}+\beta_{2} M_{i j t}+\beta_{3} Z_{i j t}+\mu_{j}+v_{t}+\varepsilon_{i j t}
$$

In this equation, the dependent variable $\left(\mathrm{Y}_{\mathrm{ijt}}\right)$ is the various obesity measures for youth $\mathrm{i}$ in DMA $\mathrm{j}$ surveyed in year $\mathrm{t}$. The regressors are the $\ln$ of the weekly hours of television fast-food restaurant advertising seen $\left(\ln \mathrm{S}_{\mathrm{ijt}}\right)$; the $\ln$ of the weekly hours spent watching television ( $\ln \mathrm{T}_{\mathrm{ijt}}$ ); a vector of demographic variables for youths, including age, race, and gender $\left(\mathrm{X}_{\mathrm{ijt}}\right)$; a vector of variables containing mother's employment status, household income, a dummy for missing income, and dummy variables indicating whether the mother is overweight $(B M I \geq 25)$ or obese $(B M I \geq 30)\left(M_{i j t}\right)$; a vector of state-specific variables including the per capita number of fast-food restaurants, the per capita number of full-service restaurants, the real cigarette price, dichotomous indicators for clean indoor air laws, the real full-service restaurant price, the real food at home price, and the real fast-food restaurant price $\left(Z_{\mathrm{ijt}}\right)$; and vectors indicating DMA $\left(\mu_{\mathrm{j}}\right)$ and year $\left(v_{\mathrm{t}}\right)$. The disturbance term is $\varepsilon_{\mathrm{ijt}}$. An advantage of the specification given by equation (6) is that it allows the amount of time spent watching television to have an effect on weight outcomes that is independent of the number of hours of fast-food restaurant advertising ads seen.

Using the definition of $\mathrm{S}_{\mathrm{ijt}}$ in equations (1) and (2), equation (6) can be rewritten as

$Y_{i j t}=\gamma_{0}+\gamma_{1} \ln K-\gamma_{1} \ln 168+\gamma_{1} \ln A_{j t}+\left(\gamma_{1}+\gamma_{2}\right) \ln T_{i j t}+\beta_{1} X_{i j t}+\beta_{2} M_{i j t}+\beta_{3} Z_{i j t}+\mu_{j}+v_{t}+\varepsilon_{i j t}$. (7) 


\section{Results}

Table 1 displays descriptive statistics for the five obesity outcomes of interest for all youths and by gender. These five outcomes are BMI, an indicator that equals 1 if a youth is obese (Obese) according to age-gender adjusted BMI ranking, and the three measures of PBF described earlier (PBF-D, PBF-C, and PBF-B). The sample sizes for PBF measures are slightly lower due to restricting the sample to non-Hispanics whites, non-Hispanics black, and Hispanics. As shown in Table 1, the means for the three PBF measures are very similar. For males, the mean PBF is between 19 and 20 percent, while for females, it is between 29 and 31 percent. The PBF estimates based on DXA are slightly higher than the estimates based on BIA. In turn, PBF-B is slightly higher than PBF-C.

To compare our estimates of PBF in NLSY97 with actual measures in NHANES, we present means and standard deviations of the three PBF variables in Table 2. We have computed these figures from NHANES 1999-2000, 2001-2002, and 2003-2004. Except in the case of male PBF-B, the means in Table 2 are larger than those in Table 1, which is likely due to under-reporting of weight in the NLSY. For males, the range is between 20 and 24 percent, while for females, it is between 29 and 34 percent. For comparison purposes, we also show the statistics for BMI and Obese in NHANES 19992000. The under-reporting of weight by females is clearly reflected in the difference between the percentage of obese females of 14 percent in NHANES and 7 percent in NLSY97.

There is a high correlation among our five body composition measures. As expected, the correlation coefficients among the three measures of PBF are very high 
within gender ranging from 0.91 to 0.99 for males and from 0.97 to 0.99 for females. BMI also is highly correlated with the measures of PBF. The correlations fall between 0.89 and 0.96 for males and between 0.91 and 0.92 for females. Given the dichotomous nature of the Obese indicator, the raw correlations between Obese and each of the other four variables are smaller. Specifically, they are between 0.67 and 0.76 for males and between 0.54 and 0.72 for females.

Table 3 reproduces the regression results obtained by CRG. Regressions in which BMI or Obese is used as the dependent variable are estimated with a slightly smaller sample, but yield results that are almost identical to those in CRG.

Table 4 presents the estimation results from two alternative specifications with the three measures of PBF. In each of the nine specification (6) regressions in Table 5, we find a positive and significant relationship between television viewing time and the PBF. All nine coefficients of advertising ads are positive and five are statistically significant. The exceptions pertain to the three coefficients for females and the male coefficient for PBF-DXA, which is consistent with the non-significant advertising coefficients in the female regressions in Table 3 from CRG.

In each of the nine specifications in Table 4, we test the hypothesis that coefficient of the $\ln (\mathrm{TV}$-time) is equal to the coefficient of the $\ln$ (Ads-aired). Similar to Table 3, we fail to reject the hypothesis that the two coefficients are the same in every case. Therefore, we estimate a second model [specification (2)] in which the $\ln$ (Adsaired) and the $\ln (\mathrm{TV}$-time) are replaced with the $\ln ($ Ads-seen). This is equivalent to constraining the coefficient of the $\ln$ (TV-time) to equal the coefficient of the $\ln$ (Adsaired). In this specification all nine coefficients are significant. 
Focusing on the gender-specific results for specification (2) in Table 4, one sees that the coefficients of the $\ln$ (Ads-seen) do not vary much, ranging from 0.58 (female PBF-D) to 0.76 (male PBF-B). The male coefficient is larger than the corresponding female coefficient except for PBF-C. The last finding aside, these results mirror those in Table 3.

One way to gauge the magnitudes of the effects is to compute their elasticities with respect to the number of ads seen (ln $S$ in the version of equation (6) that omits $\ln$ T). Given the semi-logarithmic form of the equation, the elasticity is $\gamma_{1} / \bar{Y}$, where $\bar{Y}$ is the mean of the dependent variable in the regression and $\gamma_{1}$ is the regression coefficient of $\ln \mathrm{S}$. The elasticities are presented in the left panel of Table 5 using the population mean from NHANES. All the male elasticities exceed the corresponding female elasticities, and the PBF elasticities exceed the corresponding BMI elasticities. A 10 percent increase in the number of ads seen increases each outcome by between 0.2 percent and 0.4 percent. Yet as shown below, a small absolute or percentage increase in BMI can have a substantial impact on the percentage increase in the number of obese youths. It is notable that an average of the three male PBF elasticities is almost 40 percent larger than the BMI elasticity. For females, the average PBF elasticity is 25 percent larger than the BMI elasticity.

CRG put their results into context by simulating an increase in the number of ads seen that is equal to its coefficient of variation. On average, youths view approximately half an hour per week of fast-food advertising ads. Since the coefficient of variation of this variable is approximately equal to one in each regression, these computations reveal the impacts of an increase in exposure to this type of advertising of half an hour per 
week. They only make these computations for the obesity indicator, but we compute them for all five dependent variables. Following the approach by CRG, we conduct similar simulations. As shown in the right panel of Table 5, increasing exposure to fastfood advertising by half an hour per week will increase the probability of being obese by 2.5 percentage points among males. This translates into a 17 percent increase in the number of obese male youths in a fixed population. The corresponding figures for females are a 0.6 percentage point increase and a 4 percent increase in the number of obese adolescent girls in a fixed population. The simulations for the other four continuous outcomes suggest much smaller effects, especially among males. Focusing on percentage changes, the corresponding figures range from about 1 percent (female BMI) to approximately 3 percent (male PBF-B). It should be realized, however, that only the obesity indicator is discrete. To highlight this difference, suppose that the BMI of each male and each female in our sample increased by the amount predicted in Table 5, i.e., 0.38 and 0.25 , respectively. Then the probability of being obese would rise by 1.1 percentage points for males and by 0.5 percentage points for females. These effects translate into a 7 percent increase in the number of obese male youths in a fixed population and to a 3 percent increase in the number of obese female youths. While these are smaller than those obtained directly from the regression for the probability of being obese, they are non-trivial.

\section{Discussion}

Our results indicate that exposure to fast-food restaurant advertising on television causes statistically significant increases in PBF in youths. We obtain a larger effect by using PBF rather BMI as youth obesity outcome. Our results indicate that a complete 
advertising ban would reduce BMI by about 2 percent and would reduce PBF by around 3 percent. Note that very modest changes in body composition can be associated with substantial reductions in the number of obese youths. The BMI effects translate into a 6 percent reduction in the number of obese youths by the advertising ban. Similar to CRG, we conclude that exposure to fast-food restaurant advertising on television causes statistically significant increases in the body mass index of youths and on the probability that they are obese. The obesity effect is larger in absolute value. A complete ban on these advertisements would reduce the number of obese youths by 14 percent. Another policy option alternative to banning such advertising on television could be the elimination of the tax deductibility of food advertising costs. While such a policy would still leave a considerable number of youth exposed to fast-food advertising on television, it may still result in non-trivial reductions in obesity

Since the PBF effects in Table 5 are larger than the corresponding BMI effects, it would be useful to employ an obesity indicator defined by PBF as an additional outcome. We have placed this issue on an agenda for future research because obesity cutoffs based on PBF are not yet well developed. For example, Boreham, Twisk, and Savage [27] classify male youths with PBF greater than 20 percent as obese and adolescent girls with PBF greater than 24 percent as obese. If these cutoffs are applied to our NLSY data, approximately 50 percent of males and 90 percent of females are classified as obese. Even if the cutoffs for adults recommended by the National Institute of Diabetes and Digestive and Kidney Diseases [28] for adults of greater than 25 percent for males and greater than 30 percent for females are used, approximately 22 percent of males and 60 percent of females are identified as obese. It is valuable to examine the characteristics of 
individuals classified as obese by one measure but not the other and vice versa. It also is valuable to obtain PBF cutoffs that result in the same percentage of obese youths as BMI cutoffs.

We conclude by re-emphasizing that it would be useful to develop an obesity indicator defined by the PBF, to use this outcome as an additional dependent variable, and to examine non-linear effects. These might take the form of greater sensitivity to advertising by youths just below the BMI obesity cutoff or to the corresponding PBF cutoff than by other youths. The ideal data for such an investigation would contain both actual measures of the PBF and detailed information on exposure to fast-food restaurant advertising. 


\section{Reference List}

[1] Ogden CL, Carroll M. Prevalence of Obesity Among Children and Adolescents: United States, Trends 1963-1965 Through 2007-2008. 2010. National Center for Health Statistics, Centers for Disease Control and Prevention.

[2] Holt DJ, Ippolito PM, Desrochers DM, Kelley CR. Children's exposure to TV advertising in 1977 and 2004: Information for the obesity debate. Washington, DC: FTC; 2007 Jun 1.

[3] Chou SY, Rashad I, Grossman M. Fast Food Restaurant Advertising on Television and Its Influence on Childhood Obesity. The Journal of Law and Economics 2008;51(4):599-618.

[4] Seiders K, Petty RD. Taming the Obesity Beast: Children, Marketing, and Public Policy Considerations. Journal of Public Policy \& Marketing 2007;26(2):236242.

[5] Andreyeva T, Kelly IR, Harris JL. Exposure to food advertising on television: Associations with children's fast food and soft drink consumption and obesity. Econ Hum Biol 2011;9:221-233.

[6] White House Task Force on Childhood Obesity. Solving the problem of childhood obesity. http://www.letsmove.gov/sites/letsmove.gov/files/TaskForce_on_Childhood_Obe sity May2010 FullReport.pdf . 2010. 11-28-2012.

[7] Smalley KJ, Knerr AN, Kendrick ZV, Colliver JA, Owen OE. Reassessment of body mass indices. The American Journal of Clinical Nutrition 1990;52(3):405408.

[8] Romero-Corral A, Montori VM, Somers VK et al. Association of bodyweight with total mortality and with cardiovascular events in coronary artery disease: a systematic review of cohort studies. The Lancet 2006;368(9536):666-678.

[9] Romero-Corral A, Somers VK, Sierra-Johnson J et al. Diagnostic performance of body mass index to detect obesity in patients with coronary artery disease. European Heart Journal 2007;28(17):2087-2093.

[10] Yusuf S, Hawken S, Ounpuu S et al. Obesity and the risk of myocardial infarction in 27,000 participants from 52 countries: a case-control study. Lancet 2005;366(9497):1640-1649.

[11] Yusuf S, Hawken S, Ounpuu S et al. Effect of potentially modifiable risk factors associated with myocardial infarction in 52 countries (the INTERHEART study): case-control study. Lancet 2004;364(9438):937-952. 
[12] Widhalm K, Schonegger K, Huemer C, Auterith A. Does the BMI reflect body fat in obese children and adolescents? A study using the TOBEC method. Int J Obes Relat Metab Disord 2001;25(2):279-285.

[13] Daniels SR, Khoury PR, Morrison JA. The Utility of Body Mass Index as a Measure of Body Fatness in Children and Adolescents: Differences by Race and Gender. Pediatrics 1997;99(6):804-807.

[14] Skybo T, Ryan-Wenger N. Measures of Overweight Status in School-Age Children. The Journal of School Nursing 2003;19(3):172-180.

[15] Vivan H.Heyward, Dale R.Wagner. Applied Body Composition Assessment. 2nd ed. Champaign, IL: Human Kinetics; 2004.

[16] Burkhauser RV, Cawley J. Beyond BMI: the value of more accurate measures of fatness and obesity in social science research. $J$ Health Econ 2008;27(2):519-529.

[17] Wada R, Tekin E. Body composition and wages. Economics \& Human Biology 2010;8(2):242-254.

[18] Centers for Disease Control and Prevention (CDC) National Center for Health Statistics (NCHS). National Health and Nutrition Examination Survey Data. 2011. Hyattsville, MD: U.S., Department of Health and Human Services, Centers for Disease Control and Prevention. http://www.cdc.gov/nchs/nhanes.htm. 11-282012.

[19] National Institutes of Health. Bioelectrical Impedance Analysis in Body Composition Measurement. National Institutes of Health Technology Assessment Conference Statement 1994;Available at: URL: http://consensus.nih.gov/1994/1994BioelectricImpedanceBodyta015PDF.pdf.

[20] Chumlea WC, Guo SS, Kuczmarski RJ et al. Body composition estimates from NHANES III bioelectrical impedance data. Int J Obes Relat Metab Disord 2002;26(12):1596-1609.

[21] Sun SS, Chumlea WC, Heymsfield SB et al. Development of bioelectrical impedance analysis prediction equations for body composition with the use of a multicomponent model for use in epidemiologic surveys. Am J Clin Nutr 2003;77(2):331-340.

[22] Boileau RA. Body Composition Assessment in Children and Youths. In: O.BarOr, editor. The Child and Adolescent Athlete, Encyclopedia of Sports Medicine.Cambridge, MA: Blackwell Science; 1996. 523-537.

[23] Borrud LG, Flegal KM, Looker AC, Everhart JE, Harris TB, Shepherd JA. Body composition data for individuals 8 years of age and older: U.S. population, 19992004. Vital Health Stat 11 2010;(250):1-87. 
[24] Bozoyan C, Wolbring T. Fat, muscles, and wages. Economics \&amp; Human Biology 2011;9(4):356-363.

[25] Chou SY, Grossman M, Saffer H. An economic analysis of adult obesity: Results from the Behavioral Risk Factor Surveillance System. Journal of Health Economics 2004;23(3):565-587.

[26] Angrist JD, Krueger AB. Chapter 23 Empirical strategies in labor economics. In: Orley CAaD, editor. Handbook of Labor Economics. Volume 3, Part A ed. Elsevier; 1999. 1277-1366.

[27] Boreham CA, Twisk J, Savage MJ, Cran GW, Strain JJ. Physical activity, sports participation, and risk factors in adolescents. Med Sci Sports Exerc 1997;29(6):788-793.

[28] National Institute of Diabetes and Digestive and Kidney Diseases. Weight Control Information Network. Weight-control Information Network 2006;Available at: URL: http://win.niddk.nih.gov/publications/understanding.htm\#distribution. 
Table 1: Means and Standard Deviations

\begin{tabular}{llccc}
\hline Variable & Definition & All & Male & Female \\
\hline \multirow{2}{*}{ BMI } & Body mass index & 22.10 & 22.54 & 21.65 \\
& & $(4.438)$ & $(4.581)$ & $(4.237)$ \\
Obese & Equals 1 if BMI is $\geq$ the $95^{\text {th }}$ percentile & 0.103 & 0.135 & 0.070 \\
& & $(0.304)$ & $(0.342)$ & $(0.255)$ \\
PBF-D & Percentage body fat based on DXA & 25.68 & 20.17 & 31.48 \\
& & $(8.218)$ & $(5.877)$ & $(6.052)$ \\
PBF-C & Percentage body fat based on Chumlea & 23.89 & 19.16 & 28.87 \\
& & $(8.035)$ & $(5.447)$ & $(7.275)$ \\
PBF-B & Percentage body fat based on Boileau & 24.37 & 19.92 & 29.05 \\
& & $(8.078)$ & $(6.390)$ & $(6.938)$ \\
$\ln$ (TV-time) & Time spent watching television (hours/week; & 2.65 & 2.718 & 2.579 \\
& in logs) & $(0.805)$ & $(0.795)$ & $(0.809)$ \\
$\ln ($ Ads-aired) & Hours of fast-food restaurant advertising Ads- & 1.269 & 1.265 & 1.274 \\
& aired per week in respondents DMA (in logs) & $(0.383)$ & $(0.389)$ & $(0.378)$ \\
$\ln$ (Ads-seen) $)$ & Hours of fast-food restaurant advertising ads & -1.205 & -1.141 & -1.271 \\
& seen (in logs) & $(0.911)$ & $(0.900)$ & $(0.917)$ \\
Sample size & Person-years & 7,069 & 3,665 & 3,404 \\
& & & & \\
\hline
\end{tabular}

Note: Standard deviations are in parentheses. Means and standard deviations employ the NLSY sampling weights. For the three PBF measures, the sample size is 6,979 for all, 3,625 for males, and 3,354 for females. 
Table 2: Means and Standard Deviations, Body Composition Measures, NHANES, Ages 12-18

\begin{tabular}{lccc}
\hline Variable & All & Male & Female \\
\hline \multirow{2}{*}{ BMI } & 22.82 & 22.52 & 23.13 \\
& $(7.367)$ & $(7.279)$ & $(7.463)$ \\
Obese & 0.148 & 0.153 & 0.144 \\
& $(0.450)$ & $(0.461)$ & $(0.441)$ \\
PBF-D & 28.07 & 24.12 & 33.74 \\
& $(12.15)$ & $(10.94)$ & $(9.504)$ \\
PBF-C & 25.43 & 20.35 & 30.99 \\
& $(13.42)$ & $(10.89)$ & $(11.78)$ \\
PBF-B & 24.43 & 19.89 & 29.38 \\
& $(14.14)$ & $(13.06)$ & $(12.08)$ \\
\hline
\end{tabular}

Note: Standard deviations are in parentheses. BMI and Obese are from NHANES 19992000. PBF-D, PBF-C, and PBF-B are from NHANES 1999-2000, 2001-2002, and 20032004. 
Table 3: Regression Results, Body Mass Index and Obese

\begin{tabular}{|c|c|c|c|c|c|c|}
\hline & \multicolumn{3}{|c|}{ Specification 1} & \multicolumn{3}{|c|}{ Specification 2} \\
\hline & All & Male & Female & All & Male & Female \\
\hline & \multicolumn{6}{|c|}{ A. Body Mass Index } \\
\hline \multirow[t]{2}{*}{$\ln$ (Ads-aired) } & $0.266 *$ & $0.381 *$ & 0.117 & & & \\
\hline & [1.630] & [1.365] & {$[0.557]$} & & & \\
\hline \multirow[t]{2}{*}{$\ln (\mathrm{TV}$-time $)$} & $0.474 * * *$ & $0.556^{* * *}$ & $0.380 * * *$ & & & \\
\hline & {$[4.479]$} & [4.049] & {$[3.274]$} & & & \\
\hline \multirow[t]{2}{*}{$\ln ($ Ads-seen $)$} & & & & $0.463 * * *$ & $0.547 * * *$ & $0.367 * * *$ \\
\hline & & & & {$[4.721]$} & {$[4.280]$} & {$[3.367]$} \\
\hline \multirow{2}{*}{$\begin{array}{l}\text { T-test on equality of } \\
\text { coefficients }\end{array}$} & & & & & & \\
\hline & 0.346 & 0.606 & 0.298 & & & \\
\hline R-squared & 0.193 & 0.191 & 0.236 & 0.193 & 0.191 & 0.236 \\
\hline \multirow[t]{2}{*}{ Sample size } & 7,069 & 3,665 & 3,404 & 7,069 & 3,665 & 3,404 \\
\hline & \multicolumn{6}{|c|}{ B. Obese } \\
\hline \multirow[t]{2}{*}{$\ln$ (Ads-aired) } & $0.021 * *$ & $0.028 * *$ & 0.014 & & & \\
\hline & {$[1.967]$} & {$[1.846]$} & {$[0.822]$} & & & \\
\hline \multirow[t]{2}{*}{$\ln (\mathrm{TV}$-time $)$} & $0.021 * * *$ & $0.036 * * *$ & 0.009 & & & \\
\hline & {$[3.071]$} & {$[3.414]$} & {$[1.224]$} & & & \\
\hline \multirow[t]{2}{*}{$\ln ($ Ads-seen $)$} & & & & $0.021 * * *$ & $0.036^{* * *}$ & $0.009^{*}$ \\
\hline & & & & {$[3.316]$} & {$[3.555]$} & {$[1.383]$} \\
\hline $\begin{array}{l}\text { T-test on equality of } \\
\text { coefficients }\end{array}$ & 0.961 & 0.65 & 0.805 & & & \\
\hline R-squared & 0.100 & 0.108 & 0.127 & 0.100 & 0.108 & 0.127 \\
\hline
\end{tabular}

Note: All regressions are weighted by NLSY sampling weights. T-ratios, reported in brackets, are based on standard errors that are clustered at the DMA level. Sample sizes in the regressions in panel $\mathrm{B}$ are the same as in the corresponding regressions in panel $\mathrm{A}$. All coefficients are adjusted for individual characteristics, state variables, DMA fixed effects, and year fixed effects. Individual variables include age, black non-Hispanic, Hispanic, other race, male (in regressions that are not gender-specific), family income, missing income dummy, mother overweight, mother obese, and mother employed. State variables include the per capita number of fast-food restaurants, per capita number of full-service restaurants, real cigarette price, dummies for clean indoor air laws, real fullservice restaurant price, real food at home price, and real fast-food restaurant price. ${ }^{*}: \mathrm{p}<$ 0.10 (one-tailed test); ${ }^{* *}: \mathrm{p}<0.05$ (one-tailed test); ${ }^{* * *}: \mathrm{p}<0.01$ (one-tailed test). 
Table 4: Regression Results, Percentage Body Fat

\begin{tabular}{|c|c|c|c|c|c|c|}
\hline & \multicolumn{3}{|c|}{ Specification 1} & \multicolumn{3}{|c|}{ Specification 2} \\
\hline & All & Male & Female & All & Male & Female \\
\hline & \multicolumn{6}{|c|}{ A. Percentage Body Fat - DXA } \\
\hline $\ln$ (Ads-aired) & $\begin{array}{l}0.395 * * \\
{[1.969]}\end{array}$ & $\begin{array}{c}0.427 \\
{[1.170]}\end{array}$ & $\begin{array}{c}0.323 \\
{[0.825]}\end{array}$ & & & \\
\hline $\ln (\mathrm{TV}$-time $)$ & $\begin{array}{c}0.722 * * * \\
{[4.974]}\end{array}$ & $\begin{array}{c}0.735 * * * \\
{[4.362]}\end{array}$ & $\begin{array}{l}0.595 * * * \\
{[3.319]}\end{array}$ & & & \\
\hline $\ln ($ Ads-seen $)$ & & & & $\begin{array}{c}0.706 * * * \\
{[5.236]}\end{array}$ & $\begin{array}{c}0.719 * * * \\
{[4.581]}\end{array}$ & $\begin{array}{c}0.581 * * * \\
{[3.469]}\end{array}$ \\
\hline $\begin{array}{l}\text { T-test on equality of } \\
\text { coefficients }\end{array}$ & 0.246 & 0.478 & 0.553 & & & \\
\hline R-squared & 0.574 & 0.211 & 0.243 & 0.574 & 0.211 & 0.243 \\
\hline \multirow[t]{2}{*}{ Sample size } & 6,979 & 3,625 & 3,354 & 6,979 & 3,625 & 3,354 \\
\hline & \multicolumn{6}{|c|}{ B. Percentage Body Fat - Chumlea } \\
\hline $\ln ($ Ads-aired $)$ & $\begin{array}{l}0.470 * * \\
{[2.122]}\end{array}$ & $\begin{array}{l}0.606^{* *} \\
{[1.746]}\end{array}$ & $\begin{array}{c}0.416 \\
{[0.966]}\end{array}$ & & & \\
\hline $\ln (\mathrm{TV}$-time) & $\begin{array}{c}0.681 * * * \\
{[4.316]}\end{array}$ & $\begin{array}{c}0.651 * * * \\
{[3.962]}\end{array}$ & $\begin{array}{l}0.697 * * * \\
{[3.253]}\end{array}$ & & & \\
\hline $\ln ($ Ads-seen $)$ & & & & $\begin{array}{c}0.670 * * * \\
{[4.563]}\end{array}$ & $\begin{array}{c}0.649 * * * \\
{[4.243]}\end{array}$ & $\begin{array}{c}0.682 * * * \\
{[3.406]}\end{array}$ \\
\hline $\begin{array}{l}\text { T-test on equality of } \\
\text { coefficients }\end{array}$ & 0.491 & 0.915 & 0.583 & & & \\
\hline \multirow[t]{2}{*}{ R-squared } & 0.492 & 0.215 & 0.246 & 0.492 & 0.215 & 0.246 \\
\hline & \multicolumn{6}{|c|}{ C. Percentage Body Fat - Boileau } \\
\hline $\ln$ (Ads-aired) & $\begin{array}{l}0.470 * * \\
{[2.004]}\end{array}$ & $\begin{array}{l}0.601 * \\
{[1.542]}\end{array}$ & $\begin{array}{c}0.334 \\
{[0.779]}\end{array}$ & & & \\
\hline $\ln (\mathrm{TV}$-time $)$ & $\begin{array}{c}0.733 * * * \\
{[4.616]}\end{array}$ & $\begin{array}{c}0.765 * * * \\
{[4.105]}\end{array}$ & $\begin{array}{l}0.653 * * * \\
{[3.342]}\end{array}$ & & & \\
\hline $\ln ($ Ads-seen $)$ & & & & $\begin{array}{c}0.720 * * * \\
{[4.869]}\end{array}$ & $\begin{array}{c}0.756^{* * *} \\
{[4.389]}\end{array}$ & $\begin{array}{c}0.637 * * * \\
{[3.478]}\end{array}$ \\
\hline $\begin{array}{l}\text { T-test on equality of } \\
\text { coefficients }\end{array}$ & 0.408 & 0.732 & 0.521 & & & \\
\hline R-squared & 0.482 & 0.24 & 0.299 & 0.482 & 0.24 & 0.299 \\
\hline
\end{tabular}

Note: All regressions are weighted by NLSY sampling weights. T-ratios, reported in brackets, are based on standard errors that are clustered at the DMA level. Sample sizes in the regressions in panels $\mathrm{B}$ and $\mathrm{C}$ are the same as in the corresponding regressions in panel A. See note to Table 4 for additional variables included in the regressions. The dichotomous indicator of other race is deleted since these observations are not included in the regressions. ${ }^{*}: \mathrm{p}<0.10$ (one-tailed test); ${ }^{* *}: \mathrm{p}<0.05$ (one-tailed test); ${ }^{* * *}: \mathrm{p}<0.01$ (one-tailed test). 
Table 5: Effects of Fast-Food Restaurant Advertising Ads

\begin{tabular}{lccccccc}
\hline & \multicolumn{2}{l}{$\begin{array}{l}\text { Elasticities with Respect to Fast- } \\
\text { Food Restaurant Advertising } \\
\text { Ads and Simulations }\end{array}$} & \multicolumn{2}{l}{$\begin{array}{l}\text { Effect of Half an Hour per Week Increase in } \\
\text { Advertising Exposure on Body Composition } \\
\text { Measures }\end{array}$} \\
\cline { 2 - 8 } Variable & All & Male & Female & \multicolumn{2}{c}{ Male } & \multicolumn{2}{c}{ Female } \\
\hline & & & & Absolute & Percentage & Absolute & Percentage \\
Obese & - & - & - & 2.50 & 16.63 & 0.62 & 4.30 \\
BMI & 0.020 & 0.024 & 0.016 & 0.38 & 1.69 & 0.25 & 1.10 \\
PBF-D & 0.025 & 0.029 & 0.017 & 0.50 & 2.07 & 0.40 & 1.19 \\
PBF-C & 0.026 & 0.032 & 0.022 & 0.45 & 2.21 & 0.47 & 1.52 \\
PBF-B & 0.029 & 0.038 & 0.022 & 0.52 & 2.61 & 0.44 & 1.50 \\
& & & & & & & \\
\hline
\end{tabular}

Note: For all outcomes except BMI, the absolute increase is expressed in percentage points. For BMI, the absolute increase is expressed in BMI points: weight in kilograms divided by height in meters ${ }^{2}$. Percentage changes employ the NHANES means in Table 2. 